\title{
EDUCACIÓN PÚBLICA DE CALIDAD Y EQUITATIVA: MOTOR DEL DESARROLLO Y CONSTRUCTORA DE CIUDADANÍA
}

Víctor Pérez Vera 


\section{VÍCTOR PÉREZ VERA}

Ingeniero civil industrial de la Universidad de Chile (1968). En 1972 obtuvo un Master of Science en Ingeniería Industrial en la Universidad de Michigan (Estados Unidos). En 1969 fue nombrado profesor investigador del Departamento de Ingeniería Industrial en la FCFM; en esa facultad también ocupó los cargos de Director del Departamento de Ingeniería Industrial (1980-1984 y 1988-1990), Vicedecano (1984-1985), miembro de la Comisión de Evaluación Académica (1991-1992) y Decano (1994-2002). En 1993 ocupó la prorrectoría de la Universidad de Chile. Ha publicado numerosos trabajos en revistas internacionales de corriente principal, en el área de los sistemas de información. Es autor y coautor de siete libros sobre informática, sistemas de información, bases de datos y análisis financiero, todos editados por la Editorial Universitaria. En 2010 fue nombrado rector de la Universidad de Chile. 


\section{EDUCACIÓN PÚBLICA DE CALIDAD Y EQUITATIVA: MOTOR DEL DESARROLLO Y CONSTRUCTORA DE CIUDADANÍA}

La historia de la educación en Chile muestra cómo el naciente Estado independiente ocupó el primer medio siglo de existencia en organizar un sistema educacional más o menos en forma, que rompiese con la herencia colonial de un sistema esencialmente privado y desarticulado, además de desprovisto de verdaderas oportunidades educacionales. El segundo medio siglo de vida independiente, aunque consolidó el rol del Estado en la educación, no implicó una democratización significativa del acceso a la educación. Tomaría buena parte del siglo XX concretar este proceso, durante lo que podríamos llamar "el período de oro" del Estado Docente. Sin embargo, la profunda reforma neoliberal impuesta a inicios de los años 80 del siglo pasado y en plena dictadura, logró revertir en solo un cuarto de siglo la relación entre la educación pública y la educación privada en Chile, haciendo a esta última mayoritaria al momento de celebrarse el Bicentenario de la República.

En otras palabras, tanto en educación básica como media y superior, Chile llegó al año 2010 con una educación mayoritariamente privada, situación que no existía desde la primera mitad del siglo XIX, cuando permanecía la herencia del régimen colonial. Sin embargo, en estas materias, como en otras, el péndulo de la historia a veces se acelera. Así, la imagen cada vez más plausible de un sistema educacional casi completamente privatizado ha movilizado, desde el año 2006, a crecientes sectores sociales y políticos en torno a la idea de fortalecer la educación pública.

El movimiento social que entró en escena el año 2006 logró producir un cambio significativo: los estudiantes secundarios se apoderaron por un momento del campo de discusión sobre política educacional en Chile. Desde esta perspectiva, la mayor contribución de este movimiento fue precisamente romper la inercia que se había instalado en el campo de las políticas educacionales; no es que estuviese inactivo, pero había tomado un rumbo que no le permitía abrirse a cuestionamientos más estructurales sobre los cambios que requería el sistema escolar chileno. Después de la protesta de los estudiantes, Chile fue distinto y los cambios parecieron posibles.

La combinación del sentido de urgencia y presión social, aportados por el movimiento estudiantil, hicieron posible lo que hasta hacía poco era improbable: impulsar una agenda política de transformaciones institucionales al sistema escolar. Así, en los cuatro años siguientes al agitado 2006, se propusieron más cambios institucionales al sistema escolar que en el cuarto de siglo anterior. Los cambios en la educación superior, como se sabe, quedaron pendientes.

Sin embargo, la agenda de cambios nació desbalanceada: se puso más énfasis en la presión sobre las instituciones escolares que en la generación de capacidades para responder a esa presión; más énfasis en los mecanismos de incentivo que en los de apoyo; más énfasis en generar dispositivos de accountability y control que en crear una institucionalidad escolar capaz de gestionarse sanamente; en fin, más énfasis en evaluar a los profesores que en mejorar su preparación. 
Resulta hoy obvio que las falencias y desequilibrios de las propuestas del 2006, sumadas a la nula evolución y menor solución respecto de temas que en esa oportunidad quedaron pendientes, son el antecedente inmediato de la crisis social y política de mediados de este año. Una vez más, los estudiantes de enseñanza básica, media y universitaria salieron a la calle para manifestar su disconformidad con el sistema educacional imperante en el país.

\section{UN SISTEMA ESCOLAR FRACTURADO}

¿Por qué es tan importante para un país fortalecer su educación escolar pública? Dicho en términos negativos: porque no está demostrado que la educación escolar privada pueda satisfacer todas las dimensiones del interés público involucrado en la educación. Dicho en términos positivos: la historia y la experiencia comparada enseñan que, para alcanzar los fines sociales que se espera de la educación, es necesario que el estado garantice la existencia y promueva el desarrollo de la educación pública. En otras palabras, mientras para las instituciones privadas de educación servir fines públicos es una opción entre otras posibles, para las instituciones de educación escolar pública, el servir fines públicos es una obligación, porque en ello radican su identidad y su misión.

Siendo más concretos, podríamos decir que el mandato de la educación escolar pública tiene al menos tres componentes. En primer término, las instituciones de educación pública deben garantizar el derecho constitucional de todos a acceder a una educación obligatoria y gratuita, lo que implica dar garantías de accesibilidad en las diferentes zonas geográficas, a los diversos grupos sociales, incluyendo a las minorías étnicas, a quienes pertenecen a los grupos sociales con menos recursos y a los niños con necesidades educativas especiales.

En segundo lugar, las instituciones de educación escolar pública garantizan la existencia de proyectos educativos no particularistas ni discriminatorios, en donde no solo se tolera sino que se promueve la diversidad sociocultural: la misión de la educación pública no es aumentar la diversidad de ofertas en el mercado educacional, sino promover la diversidad al interior de cada una de las instituciones. Finalmente, la educación pública debe desarrollar proyectos educacionales considerados de interés común, trabajando e invirtiendo en áreas del conocimiento y la cultura cuyo valor privado puede ser muy bajo, pero de gran impacto social; así como campos que, aunque no satisfagan criterios de rentabilidad económica, son esenciales para el desarrollo cultural y social de una nación, como las artes, las humanidades o las ciencias sociales.

La escuela y el liceo son considerados como uno de los espacios privilegiados para preparar a los niños, niñas y jóvenes, no solo para el desarrollo de su intelecto y la adquisición de las herramientas necesarias en una sociedad globalizada, impulsada por el conocimiento continuo, sino que también para la convivencia ciudadana en una sociedad pluralista, que les permita desarrollar la capacidad de relacionarse con personas provenientes de realidades diferentes a las de sus propias familias. Estos objetivos son imposibles de alcanzar si nuestro sistema escolar distribuye tempranamente a los 
estudiantes entre los diversos establecimientos de acuerdo a las condiciones socioeconómicas de sus familias. La segregación temprana impide conocer la diversidad de nuestra sociedad y aprender a convivir con los otros, sin permitir la construcción de un país más integrado y tolerante. Asimismo, reduce considerablemente las posibilidades de una educación de calidad para todos los niños y jóvenes, puesto que parte de estos aprendizajes es logrado por las capacidades y habilidades del resto de los compañeros y compañeras de aula, donde se concentran solo niños vulnerables.

Al situar a nuestro país en el contexto internacional, es posible apreciar a partir de los antecedentes recogidos de la prueba PISA -que mide el desempeño de los estudiantes de 15 años en las disciplinas de lectura, matemática y ciencias-, que Chile, en el año 2009, presentaba el sistema escolar más segregado de todos los países miembros de la OCDE, tanto entre estudiantes de grupos vulnerables como de mayor nivel socioeconómico. Incluso, al ampliar la muestra a los 65 países participantes de esta prueba, el sistema escolar chileno se presentaba como el segundo más segregado. Y esto, que nos debe escandalizar y avergonzar, se ha convertido en una noticia más, entre muchas, que los líderes de opinión pública parecen olvidar al día siguiente. Sin embargo, estos datos brutales explican por sí mismos la crisis social en que ha desembocado la pasividad de la autoridad política de turno para poner fin a un sistema fracturado, odioso y probadamente inútil al desarrollo del país.

\section{LA FORMACIÓN DE PROFESORES COMO PRIORIDAD}

Partiendo de la base de que existe consenso respecto a que el modelo de financiamiento y gestión municipal para la enseñanza escolar ha fracasado rotundamente y su reformulación requiere de, en primer lugar, una mirada integradora, y luego de una decisión política contundente y consensuada, estimamos que desde el punto de vista de la formación de profesores se pueden materializar varias propuestas concretas que se debiesen impulsar en el ámbito de la enseñanza escolar.

Primero, que el Estado exija estándares de calidad superiores a las carreras docentes, lo que debiera implicar una sensible reducción del número de instituciones formadoras y carreras de pedagogía. Esto obliga a repensar la institucionalidad de acreditación de carreras.

Segundo, ser más selectivos en los alumnos que pueden ser admitidos en la carrera de Pedagogía, lo que supone exigir un mínimo elevado de puntaje PSU, así como incentivos para dichos alumnos y avanzar hacia mecanismos complementarios de selección que permitan reconocer el talento en alumnos que no han tenido las oportunidades de una educación que prepare para la PSU, junto con calibrar la vocación y el compromiso social.

Tercera, mejorar la calidad de las escuelas de educación. El Estado debe procurar que existan escuelas de Pedagogía, de mejor calidad, a las cuales pueda exigir más, pero también apoyar y monitorear mejor.

De acuerdo a este análisis, y en el entendido que la Universidad de Chile por mandato, misión e historia tiene un compromiso irrenunciable con este eje de desarrollo, 
hemos decidido impulsar un proyecto institucional en el área de la educación que contemple abordar la formación inicial de profesores en todos sus niveles, así como los programas de educación continua. En concreto, estamos buscando potenciar los programas existentes a través del fortalecimiento del cuerpo académico, la modernización de los programas de estudio, el incremento de la matrícula y la diversificación de las áreas disciplinarias. Nuestro compromiso es elevar el nivel de calidad de la formación inicial docente en Chile, constituyéndonos en un referente de calidad para el resto del sistema de formación, de acuerdo a exigentes estándares internacionales.

\section{EDUCACIÓN SUPERIOR PÚBLICA DE CALIDAD CON EQUIDAD: EJE DEL NUEVO TRATO}

Con frecuencia, la literatura y el sentir de algunos en el mundo académico contraponen la calidad y la equidad como fines, ambos deseables, pero contrarios entre sí, porque la focalización en uno supuestamente debilitaría el otro. La visión de la Universidad de Chile es otra. En el siglo XXI la disyuntiva entre equidad y calidad ha quedado obsoleta porque la calidad exigida a la educación superior es inalcanzable sin equidad. Por lo mismo, una cosa que está fuertemente en juego en caso de perderse la lucha por la equidad es, precisamente, perder la calidad que hoy en día se espera de una Universidad de primer nivel. La razón de esto es, por una parte, la estrecha relación entre equidad y diversidad y, por la otra, el rol fundamental que hoy en día juega la diversidad en el éxito o fracaso del desempeño profesional, empresarial y político de personas y colectividades. La equidad se logra facilitando el acceso a la Universidad a personas con diversidad de circunstancias de origen que no inciden en su talento y capacidad. Por lo mismo, la equidad no es abrir las puertas a ciertos grupos de alumnos, sino dar a todos los alumnos la posibilidad de abrir sus mentes, para que en un mundo marcado por la diversidad sean más efectivos en su actuar profesional y más democráticos en su participación ciudadana.

Un primer eje ordenador en toda discusión sobre educación superior es aclarar el rol que les corresponde a las universidades estatales y las privadas. La ausencia de claridad lleva a pensar que la única diferencia es la propiedad pero, aparte de esta obviedad, todas son iguales, y por lo tanto las políticas conducen una competencia en el mercado. El efecto evidente es que la competencia se hace cargo de la conducción de las universidades y el rol de las universidades públicas es dominado por las condiciones de supervivencia. Esto constituye una fuerza que afecta fatalmente a las universidades estatales, enfrentándolas diariamente con la disyuntiva entre su misión y la orientación de mercado para garantizar, sino su supervivencia, al menos su relevancia.

Nos parece urgente fortalecer la institucionalidad del Estado en la educación superior en dos ámbitos: la fiscalización, mediante la creación de una Superintendencia de Educación Superior, y en el tema de la formulación y evaluación de políticas, mediante una Subsecretaría de Educación Superior. En su momento esta idea fue propuesta por el Consejo Asesor Presidencial para la Educación Superior y posteriormente fue reiterada 
en el año 2009 por el Consejo de Rectores de las Universidades Chilenas (CRUCH). Hoy, afortunadamente, ha vuelto a ser materia de discusión pública.

En síntesis, la propuesta del Nuevo Trato con el Estado impulsada por la Universidad de Chile desde el año 2007 propone que las universidades estatales no pueden ni deben competir como una más. En primer lugar no pueden porque enfrentan dificultades sustantivas en las condiciones en que operan, y segundo, y más profundo, porque deben cumplir una serie de condiciones que son propias de una institución del Estado, que por definición se debe a todos. Así, el propósito de la política del Nuevo Trato es fortalecer las universidades estatales públicas, asegurar la calidad de la docencia y la investigación que ellas realizan y proveer las condiciones para que ellas se constituyan en un pilar del desarrollo nacional y regional.

Lograr lo anterior requiere cambios impostergables. Hemos señalado que Chile carece de un modelo sustentable de Universidad pública, lo que pone en grave riesgo la existencia y misión misma de las universidades estatales o, peor aún, podría conducirnos a una existencia precaria basada simplemente en asegurar una supervivencia huérfana de toda misión superior. Ello, en un mundo en que el conocimiento será la gran herramienta para asegurar un acceso a iguales oportunidades, a los frutos del progreso, a una mejor calidad de vida de las chilenas y chilenos en el siglo XXI.

\section{LAS RAZONES DE LA PRIMERA UNIVERSIDAD DEL PAÍS}

Durante 18 años la Universidad de Chile fue intervenida políticamente y sufrió las consecuencias de una brutal política de Estado orientada a desmantelarla, a afectar derechamente su sustentabilidad. Gracias a la cohesión, trabajo y compromiso de toda nuestra comunidad universitaria, tal política de Estado no pudo destruirnos. Más aun: a 20 años de recuperada la democracia y sin que el Estado haya reparado los efectos de tal política, seguimos siendo la Universidad que muestra los mejores indicadores de productividad científica en el país. A modo de ejemplo, ocupamos el lugar 9 en el ranking latinoamericano de universidades que realiza el grupo SCImago y que publica un ranking anual de instituciones con mayor investigación científica en el mundo. Somos la Universidad chilena mejor posicionada en ese ranking.

Nuestro desarrollo, productividad académica y la contribución que nuestra comunidad universitaria hace al país en la formación de profesionales y graduados, son de una contundencia única en el sistema universitario nacional. Asimismo, el alto nivel de los estudiantes que captamos, así como el éxito que tienen los profesionales que egresan de nuestras aulas, podrían tener mucha mayor proyección en beneficio del país que lo actualmente alcanzado.

Y ello sería posible si tuviésemos un esquema universitario que facilitara nuestro quehacer, y no que lo obstaculizara, como es en la actualidad. Si Chile quiere llegar a ser un país desarrollado, la experiencia internacional señala que -sin excepción- los países que lo han logrado han puesto como objetivo estratégico previo el tener universidades de calidad internacional. Y la Universidad de Chile tiene la tradición y misión y, tan 
importante como eso, tiene la capacidad académica, rigor y oficio que son condición necesaria para cumplir, en el corto plazo, nuestro objetivo: llegar a ser una Universidad pública de calidad internacional, para contribuir a hacer de Chile un país desarrollado económica, social y culturalmente.

Nuestro presupuesto anual es del orden de $\$ 400.000$ millones, del que el Estado solo aporta menos del 10\%. Todos nuestros balances y estados financieros son auditados externamente y son publicados en medios de prensa, a lo que no están obligadas las universidades no estatales. En este sentido, en general, la normativa aplicable a las universidades establece aspectos mínimos de regulación, existiendo amplios espacios para el ejercicio de la autonomía institucional, salvo en el caso de las universidades estatales, las que cuentan con regulaciones administrativas más específicas. Todos los fondos que recibimos, del Estado o del sector privado, son fiscalizados por la Contraloría General de la República, lo que no sucede, como se ha señalado, con los fondos públicos que el Estado entrega a las universidades que no son estatales.

Somos una Universidad estatal pero solo recibimos 10 de cada 100 pesos de nuestro presupuesto. Esto no es entendible por los rectores de las 8 universidades que están antes que nosotros en el ranking de SCImago, al que ya me he referido. Esas 8 universidades son estatales, y 6 son brasileñas. Una de estas, la Universidad de Sao Paulo, está en el primer lugar en Latinoamérica, pero está en el lugar 16 de ese ranking a nivel del mundo. La Universidad Autónoma de México está segunda en Latinoamérica y en el lugar 88 a nivel mundial. Nosotros estamos en el lugar 9 de Latinoamérica, pero en el lugar 380 a nivel mundial, y la siguiente Universidad chilena está en el lugar 591.

Desde la Universidad de Chile exigimos al Estado una nueva Ley de Educación Superior, que garantice la existencia y desarrollo de las universidades estatales, que las financie en al menos el 50\% de sus actuales presupuestos -en Brasil, en Finlandia y otros países de la OCDE el aporte estatal a las universidades del Estado es sobre el 65\% de sus presupuestos-, y que dé claras orientaciones respecto de sus deberes y derechos, para que así estas puedan enfrentar desafíos mayores contando con un trato claro con la sociedad. La autonomía académica, económica y administrativa es un principio rector que debe resguardarse en la formulación de tal política, atendiendo a la naturaleza de la actividad de educación superior que dista en mucho de otras funciones de otras instituciones del Estado. Conjuntamente, la política debe dar claridad en las condiciones en que las universidades privadas están invitadas a contribuir con la provisión de bienes públicos atendiendo a las funciones y la calidad con que desarrollan docencia, investigación y extensión.

\section{MÁS QUE UN DESAFÍO: ESTAMOS FRENTE A UNA OBLIGACIÓN ÉTICA}

Parte importante del debate sobre la equidad en educación ha apuntado a la necesidad de enfocar las políticas públicas en torno a mejorar significativamente la calidad. Se han conseguido avances indudables en cobertura y acceso, y sin embargo estos, los logros, están muy lejos de las expectativas que en materia de equidad tiene la sociedad chilena. 
Existe una amplia brecha de equidad socioeconómica y geográfica que no ha logrado ser disminuida eficazmente. Las coberturas correspondientes a las familias pertenecientes a los dos quintiles de mayores ingresos económicos alcanzan niveles equivalentes a los países más desarrollados, mientras que la cobertura de los quintiles más bajos se mantiene en niveles muy reducidos. La brecha en el acceso a la educación superior entre jóvenes pertenecientes al primer y quinto quintil de ingreso es de más de cuatro veces.

Las consecuencias sociales de esta brecha son imprevisibles, aunque, de alguna manera, durante los últimos meses ya se han esbozado matices que debieran preocupar en las esferas de toma de decisiones. Creemos que el rol que ha jugado el Estado en educación durante los últimos 30 años hoy se encuentra frente a potentes imperativos de cambio. El movimiento social y ciudadano no ha hecho más que desvelar la urgencia de abordar el derecho a una educación pública de calidad y de acceso universal como una obligación ética. Se ha puesto en relieve que el ejercicio de un derecho no puede estar sujeto a la capacidad de pago o endeudamiento de las personas, ni a los precios de mercado ni menos a la voluntad de la autoridad de turno.

Por estos días, no solo los actores sociales y políticos que debatimos y proponemos mejores alternativas para el desarrollo de la educación ponemos mucho en juego: la República -concebida esta como un espacio plural donde la paz social permite el crecimiento de la comunidad toda- está en un punto de inflexión. En estas horas cobra sentido aquello de la crisis como oportunidad para el cambio. Como actores protagonistas de esta oportunidad, tenemos todo el derecho a demandar acuerdos y compromisos, así como también una legislación de futuro, a partir de la cual la educación se transforme en un factor habilitador de la felicidad de las personas, y así dejar atrás, como un mal recuerdo, lo que ha venido siendo desde hace más de treinta años: un motivo de angustia familiar y desarticulación social y ciudadana. 